\title{
Assessment of blasting induced effects on medical 316 LVM stainless steel by contacting and non-contacting thermoelectric power techniques
}

\author{
H. Carreon ${ }^{1, *}$, S. Barriuso², G. Barrera ${ }^{1}$, J. L. González-Carrasco ${ }^{2,3}$, F. G. Caballero ${ }^{2}$ \\ ${ }^{1}$ Instituto de Investigaciones Metalúrgicas (UMSNH-IIM) \\ Ciudad Universitaria, Morelia, Mexico \\ ${ }^{2}$ Centro Nacional de Investigaciones Metalúrgicas (CENIM-CSIC), \\ Avda Gregorio del Amo 8, E28040 Madrid, España. \\ ${ }^{3}$ Centro de Investigación Biomédica en Red en Bioingeniería, Biomateriales y \\ Nanomedicina (CIBER-BBN), Madrid, España
}

\begin{abstract}
Grit blasting is a low cost surface modification treatment widely used to enhance mechanical fixation of implants through increasing their roughness. As a result of the severe surface plastic deformation, beneath the surface it produces additional effects such as grain size refinement, work hardening and compressive residual stresses, which are generally evaluated with destructive techniques. In this research work, the blasting induced effects by $\mathrm{Al}_{2} \mathrm{O}_{3}$ and $\mathrm{ZrO}_{2}$ particles and their evolution after annealing at $700^{\circ} \mathrm{C}$ were evaluated in 316LVM (Low Vacuum Melting) stainless steel specimens using two non-destructive thermoelectric techniques (NDTT), the non-contacting and contacting thermoelectric power measurements. Microstructural analysis and microhardness measurements performed beneath the blasted surface reveals that the non-contact NDTT results correlate well with the reversion of the $\alpha$ '-martensite developed during blasting, whereas the contact NDTT results are closely related to the grain size refinement and work hardening and the expected evolution of compressive residual stresses. Potential of these techniques to monitor subsurface changes in blasting processes and others severe surface plastic deformation techniques are clearly envisaged.
\end{abstract}

Keywords: Grit Blasting; Thermoelectric Measurements; Residual Stresses; Biomaterial 
*Corresponding author: tel: + 011-52-443-316-7414. e-mail: hcarreon@umich.mx

\section{INTRODUCTION}

It is well known that surface properties play an important role in metallic materials used in bio-medical applications. Since the biological response is correlated directly with surface properties it is comprehensible the intense activity in superficial modification by physics or chemistry methods in this field. Grit blasting, one of the most popular surface modification of metallic biomaterials, enhances the mechanical fixation of the implant through the increase in roughness [1-3]. Roughening is developed by bombarding the surface with a high-velocity jet of ceramic particles, being the final roughness a function of the processing parameters (pressure, distance, time,...) and blasting particles (nature, shape, size). As the plastically deformed surface layer tries to expand relatively to the intact interior of the specimen, residual compressive stress gradients develops perpendicular to the surface at shallow depths with a maximum value at a depth in the range of 5 to $60 \mu \mathrm{m}$. This surface treatment also may cause subtle variations in the subsurface material properties, such as increased hardness and grain size refinement, which are consequences of the significant plastic deformation through cold work. Blasted affected zones may extend to a depth of up to about $200 \mu \mathrm{m}$. The subsurface hardening and the near-surface compressive stress gradient play a beneficial role by retarding fatigue crack nucleation and further growth, ultimately extending the fatigue life of the metallic part [4]. Blasting induced effects are usually evaluated by the combination of different techniques such as X-Ray diffraction (XRD) or synchrotron radiation X-ray diffraction (SR-XRD) to determine the residual stress state; scanning electron microscopy (SEM) to assess microstructural changes, and microhardness testing to determine the hardening degree. 
Alternative methods for nondestructive stress evaluation are neutron diffraction, magnetic methods (Barkhausen noise and magnetostriction), thermal methods, ultrasonics, and eddy current methods. Eddy current and ultrasonic methods have been considered to be the most promising non-destructive techniques. However, an important disadvantage of grit blasting is that it makes the surface of the specimen rough, which not only negates some of the positive effects of compressive residual stresses via unwanted stress concentrations, but also prevents the accurate assessment of the prevailing stresses. In contrast, the conventional thermoelectric techniques that are used in non-destructive materials characterization are so sensitive to intrinsic material variations regardless of shape and surface quality of the specimen to be tested. Thermoelectric power measurements were proven to be a powerful technique to monitor the amount of atoms in solid solutions (i.e. precipitation and dissolution processes) [5], the dislocation state of the material (i.e. deformation and recovery) [6-8] and the residual stresses after surface deformation treatment [9].

In this work, two non-destructive thermoelectric techniques (NDTT), the noncontacting and contacting thermoelectric power measurements were used to analyze the sandblasting induced changes on the biomaterial 316LVM (Low Vacuum Melting) austenitic stainless steel blasted with two different types of particles, namely, microspheres of $\mathrm{ZrO}_{2}\left(125-250 \mu \mathrm{m}\right.$ in size) and angular $\mathrm{Al}_{2} \mathrm{O}_{3}$ particles ( 750 $\mu \mathrm{m}$ in size), yielding either fined or coarsed rough surfaces, respectively. Detailed information on the microstructural induced effects and subsurface mechanical properties were published elsewhere [10-12]. Here the nondestructive evaluation of the involved microstructural changes in the blasted steel is used to assess the global subsurface damage. Advantages of using nondestructive techniques during manufacturing are envisaged. 


\section{THERMOELECTRIC POWER}

Thermoelectricity is caused by coupled transport of heat and electricity in metals, which can be exploited for materials characterization. In general, the thermoelectric methods are based on the Seebeck effect that is commonly used in thermocouples to measure temperature. The contacting thermoelectric technique monitors the thermoelectric power (TEP) of metallic conductor materials, which is affected by the different types of defects present in the atomic lattice such as atoms in solid solution, precipitates and dislocations. The TEP value of the sample is a measure of the magnitude of the induced potential difference at the metal contacts in response to the temperature gradient across the sample [13]. Several parameters can affect the changes in TEP of the test sample to be inspected. The most important parameters affecting the thermoelectric measurements are those associated with volumetric and contact effects. The volumetric effect is closerelated to the thermoelectricity phenomena by the kinetics of the diffusion of electrons throughout the material. This effect is mainly affected by chemical composition, different heat treatment, precipitation process, grain boundaries, texture and fatigue of the material $[14,15]$. The contact effects are related to the imperfect contact between the test sample and the reference probe, amount of pressure applied to the probe, temperature of hot and cold junctions and probe material [16].

On the other hand, when the material gradient properties are presented at the surface or subsurface region such as local plastic deformation, fretting, residual stress, localized texture, cold work, etc., the material properties variation can be detected more efficiently using the surrounding intact material as the reference electrode; thus provides perfect interface between the region to be tested and the surrounding material [17-21]. 
This measurement process is called non contacting thermoelectric technique in which the idea is to sense the weak thermoelectric currents around inclusions and other types of inhomogeneities or imperfections when the specimen to be tested is subjected to directional heating or cooling by using a high-sensitivity magnetic sensor. An external heating or cooling is applied to the specimen to produce a temperature gradient in the region to be tested. This leads to that different points of the boundary between the host material and the imperfection will be at different temperatures, therefore also at different thermoelectric potentials. These potential differences will produce opposite thermoelectric currents inside and outside the imperfection. The thermoelectric currents form local loops that run in opposite directions on the opposite sides of the imperfection relative to the prevailing heat flux. These thermoelectric currents can be detected by magnetic sensing of the flux density $\boldsymbol{B}$ even when the imperfection is buried below the surface and the magnetic sensor is far away from the test sample [22].

\section{MATERIAL AND THERMOELECTRIC METHODS}

An austenitic stainless steel 316 LVM with the approximate composition of Fe-17.5Cr14.1Ni-2.9Mo-1.6Mn-0.5Si-0.02C-0.07Cu-0.06N-0.001S wt\% was used in this study. The steel was supplied as a bar. Specimens of $20 \mathrm{~mm}$ in diameter and $2 \mathrm{~mm}$ thick were machined and grit blasted by the implant manufacturer (SURGIVAL, Valencia, Spain). Grit blasting was performed with two different types of particles under a pressure of $350 \mathrm{kPa}$ for $2 \mathrm{~min}$ and the distance between the nozzle and the target surface was $20 \mathrm{~cm}$. A first set of samples (Zirconia) was blasted using $\mathrm{ZrO}_{2}$ embedded in silica vitreous phase microspheres sized between $125 \mu \mathrm{m}$ and $250 \mu \mathrm{m}$. The second set of samples (Alumina) was blasted with alumina angular particles $\mathrm{Al}_{2} \mathrm{O}_{3}$ of $\approx 750 \mu \mathrm{m}$. For comparative purposes, unblasted specimens were ground with consecutively finer SiC 
papers, and finely polished with diamond paste and colloidal silica $(0,5 \mu \mathrm{m})$ to remove the slight layer of disturbed metal.

Roughness of the as-processed specimens was determined with a profilometer Mitutoyo Surftest 401 averaging 3 measurements of $4 \mathrm{~cm}$ in length. Microstructural characterization of the surface morphology and cross sections of the treated and untreated specimens was carried out by using a SEM (JEOL-6500F) equipped with a field emission gun (FEG) and coupled with an energy dispersive X-ray (EDX) system for chemical analysis. In order to preserve the original blasted surface during sectioning and to avoid artifacts during the measurements performed beneath the surface, selected specimens were electrolytically coated with a fine layer of $\mathrm{Cu}$. The grain structure was revealed by Backscattered Electron Images (BEI) obtained on fresh grinded and polished surfaces.

Hardness Vickers was measured on transverse polished samples with a microhardness equipment (Wilson). Loads of $10 \mathrm{~g}$ applied during $10 \mathrm{~s}$ were used. Hardness profiles were obtained from the near surface to a depth far away from the blasted affected zone. Each value corresponds to average values of 5 indentations.

In this experimental work, we conducted a detailed investigation of the material properties that significantly change during grit blasting in order to establish how they individually and collectively affect the thermoelectric measurements and to verify that the residual stress effect dominates the outcome of the measurement. However, it is important to mention the interesting role that cold work could play in the surface treatment and obviously on the final interpretation of the results. It is well known that the principal change in the hardness due to cold work occurs simultaneously with the matrix-material recrystallization. On actual grit blasted specimens the residual stress and cold work effects can be best modified by chosen adequate heat treatments that 
simulate thermally activated stress release. In the present case, the blasted 316 LVM specimens were annealed at $700^{\circ} \mathrm{C}$ for $2 \mathrm{~min}, 10 \mathrm{~min}$ and $1 \mathrm{~h}$, and subsequently then aircooled down to room temperature.

\section{TEP measurements}

The contacting TEP measurements were performed using a calibrated TECHMETAL thermoelectric contact apparatus. The sample is pressed between two blocks of a reference metal (pure copper). One of the blocks is at $15^{\circ} \mathrm{C}$, while the other is at $25^{\circ} \mathrm{C}$ to obtain a temperature differenc $T$. A potential difference $V$ is generated at the reference metal contacts. The apparatus does not give the absolute TEP value of the sample $\left(S^{*}\right)$, but a relative TEP $(S)$ in comparison to the TEP of pure copper $\left(\mathrm{S}_{0}{ }^{*}\right)$ at $20^{\circ} \mathrm{C}$. The relative TEP value (S) is given by $S=S^{*}-S_{0}{ }^{*}=\Delta V / \Delta T$. The measurements are performed very quickly ( $<1 \mathrm{~min})$ and precisely $( \pm 0.5 \%)$, with a resolution of about $0.001 \mu \mathrm{V} / \mathrm{K}$.

On the other hand, in the non-contacting TEP measurements, each specimen is mounted into two pure copper supporters which are perforated by a series of holes and equipped with sealed heat exchangers to facilitate efficient heating and cooling and then mounted on a nonmagnetic translation table for scanning. In order to get a better heat transfer between the specimen and the copper heat exchangers, a layer of silicone heat sink compound was applied. One of the copper supporters is at $15^{\circ} \mathrm{C}$, while the other is at $25^{\circ} \mathrm{C}$. The temperature gradient is kept at $\sim 1.2^{\circ} \mathrm{C} / \mathrm{mm}$ in all non-contacting TEP measurements, which is more than sufficient to produce detectable magnetic signals in the 316 LVM stainless steel. A pair of fluxgate sensors is used in a gradiometric arrangement in order to detect the thermoelectric signals from the grit blasted zone. The 
inspection of the specimen is realized at the horizontal sensor polarization. The lift-off distance between the primary sensor and the sample surface is $\sim 2 \mathrm{~mm}$.

\section{RESULTS AND DISCUSSION}

Surface SEM examination showed that blasting of the alloy causes a severe surface plastic deformation for the Zirconia and Alumina samples as shown in Figures 1 and 2. The blasting process also leaves a rough surface with an average roughness, $\mathrm{Ra}$, of 0.9 $\mu \mathrm{m}$ and $6.7 \mu \mathrm{m}$ for the Zirconia and Alumina samples, respectively. These differences should be understood within the framework of the specific features that distinguish the $\mathrm{ZrO}_{2}$ and $\mathrm{Al}_{2} \mathrm{O}_{3}$ particles. As mentioned previously, the $\mathrm{ZrO}_{2}$ particles are rounded, whereas the $\mathrm{Al}_{2} \mathrm{O}_{3}$ ones are some three times larger and have a rough surface characterized by edge-like facets. Therefore, the Zirconia particles produce a more homogeneous deformation without grinding down the material, unlike the $\mathrm{Al}_{2} \mathrm{O}_{3}$ ones. As expected, contamination with ceramic particles, obviously remnants of the blasting particles, is also observed. Heat treatment of the samples causes a change in the aspect of the surface from a glazed gray to a rather dark gray color due to the moderated oxidation process, but changes in the surface roughness was not significant as shown in Figures 1 and 2.

In addition to the irregular rough surface morphology, grit blasting produces significant subtle microstructural variations that are consequence of the severe plastic deformation through cold work [9,11]. Consequently, a detailed cross sectional examination was performed on the blasted specimens before and after heat treatments. Figures 1 and 2 show representative cross sectional BEI images of the alumina and Zirconia blasted samples, respectively. For simplicity, besides those of the as-blasted condition only images corresponding to the longest thermal treatment are shown $\left(700^{\circ} \mathrm{C} / 1 \mathrm{~h}\right)$. In the as-blasted conditions, Fig. 1a and 2a, three zones can be 
distinguished without a clearly defined borderline. The zone just beneath the surface is characterized by an ultrafine microstructure containing randomly distributed nanometerscale grains. This zone seems to be rather larger for the alumina $(30 \mu \mathrm{m}$ thick $)$ than for the Zirconia samples ( $\approx 15 \mu \mathrm{m}$ thick). The next zone (about $50 \mu \mathrm{m}$ depth) presents highly deformed grains, as well as twins and martensite needles without well defined grain frontiers. The third and deepest zone shows a progressive change in the backscattered signal, which shows a slight change in the crystallographic orientation. The grains are not altered for depth of about $100 \mu \mathrm{m}$ and $200 \mu \mathrm{m}$ for Zirconia and Alumina samples, respectively. A detailed examination of the heat treated specimens, Fig. $1 \mathrm{~b}$ and $2 \mathrm{~b}$, failed to show changes in the pattern of the microstructure and in the grain size.

Microhardness measurements of the Alumina and Zirconia blasted specimens in the untreated condition, Figure 3, reveals a gradient in hardness along a line perpendicular to the blasted surface with a maximum of $360 \mathrm{HV} 0.01$ close to the surface. In both cases, hardness decreases with increasing depth, achieving a near constant value of about $180 \mathrm{HV} 0.01$ at a depth of $\sim 200 \mu \mathrm{m}$ and $\sim 100 \mu \mathrm{m}$ into the bulk, depending on whether the blasting was performed with particles of $\mathrm{Al}_{2} \mathrm{O}_{3}$, Fig. 3a, or $\mathrm{ZrO}_{2}$, Fig. 3b respectively.

Thermal treatments at $700^{\circ} \mathrm{C}$ do not significantly influences the hardness gradients, although depending on the relative position to the blasted surface slight changes in hardness are observed. To make easier the comparison, hardness values of blasted specimens with and without heat treatment are compared in Figure 4 at depths of about 10, 100 and $200 \mu \mathrm{m}$ from the blasted surface. Although differences in hardness are small, they are out of the scattering, thus some comments are pertinent to the observed trend. It is worth mentioning that hardness gradient is the consequence of the 
sum of several factors, with different specific weights each other depending on the distance to the surface [10]. There are at least two factors that could account for the microhardness evolution: the presence of $\alpha$-martensite, which has higher hardness than the austenite, [23] and the grain refinement, as the Hall-Petch expression predicts [24, 25]. In our case, we assumed that sub-surface $\alpha$-martensite formed by plastic deformation is reversed to austenite after the heat treatment. Experimental evidence is provided by the fact that heat treated blasted samples could be monitored by the noncontacting equipment after only 2 minutes. Despite both samples have approximately the same quantity of ' $\alpha$-martensite phase, the decrease in hardness for the Alumina blasted specimens is more relevant at around $100 \mu \mathrm{m}$ from the surface, which is consistent with the formation of $\alpha^{\prime}$-martensite at deeper regions [11]. Further increase in hardness after 10 minutes can be associated with the grain size refinement associated to the reversion of the martensite. The diffusionless reverse transformation occurred irrespective of heating rate during continuous heating, resulting in lath-shaped austenite with high dislocation density [26]. The slight softening observed after $1 \mathrm{~h}$ beneath the alumina blasted surface is somewhat puzzling. It can be speculated that since plastic deformation at this zone was more severe, recrystallization occurs at lower temperatures allowing a grain growth. Variations in hardness at around $200 \mu \mathrm{m}$ in depth are irrelevant, which is consistent with the absence of blasting induced effects.

All the 316LVM stainless steel specimens were tested using the contacting, Fig. 5, and non-contacting, Fig. 6, thermoelectric techniques. As can be seen, inspection of the unblasted specimens did not reveal any TEP variation, irrespectively the application or not of heat treatments. Interestingly, blasted specimens failed to reveal any change in the magnetic flux density when using the non-contacting technique, Fig. 6. This feature is associated to the presence of $\alpha^{`}$-martensite that, due to its ferromagnetic behavior, 
affected negatively the detection of the magnetic field produced by thermoelectric currents around the blasting affected zone. Annealing favored its reverse transformation to austenite, [27] thus the magnetic signal was recovered. Flux density decreased with increasing the soaking time and after $1 \mathrm{~h}$ was nearly identical to that observed for the unblasted specimens. After the first partial stress relaxation, the measured magnetic flux density decreased by $\sim 9 \mathrm{nT}$ with the two different types of blasting processes using $\mathrm{ZrO}_{2}$ and $\mathrm{Al}_{2} \mathrm{O}_{3}$ particles respectively. In comparison, on the second partial stress relaxation treatment at $700^{\circ} \mathrm{C}$ for 10 mins the magnetic flux density was approximately $\sim 82 \%$ lower. For a given soaking time before full stress release, the magnetic flux density was nearly identical to that observed for the unblasted specimens [8].

TEP measurements with the contacting technique revealed an increase in the relative TEP value of the blasted specimens with regards to the unblasted condition, with a somewhat higher value for the Zirconia blasted specimens. Annealing at $700^{\circ} \mathrm{C}$ caused a decrease in the relative TEP, being differences insignificant when increasing the soaking time. After $1 \mathrm{~h}$ of annealing the relative TEP value was much higher than that corresponding to the unblasted conditions, which correlates well with the remaining blasting induced effects manifested by significant hardness gradients.

Overall this study reveals that the contact technique is more sensitive to the presence of subtle material variations produced by blasting compared to the noncontact technique. This phenomena can be explained by the fact that the microstructural changes occurs mainly at the surface or near surface of the specimen, while the noncontact TEP measurements averages material properties throughout the entire thickness of the sample.

\section{CONCLUSIONS}


It has been found that the contacting thermoelectric technique is associated directly with the subtle material variations such as such as grain size refinement, work hardening and compressive residual stresses due to plastic deformation produced by the manufacturing process of grit blasting in a 316LVM stainless steel. While, the TEP measurements clearly demonstrated that the non-contact NDTT technique is so sensitive with the reversion of the $\alpha$ '-martensite developed during blasting. In general, the thermoelectric inspection is completely insensitive to geometrical edge effects, which is an absolute necessity in many applications where cold working and residual stress must be assessed in the vicinity of sharp stress concentrators.

\section{ACKNOWLEDGMENTS}

This work was performed at UMSNH (Mexico) and CENIM-CSIC (Spain) with a partial funding from CONACYT (Mexico) under project CB-80883 and MAT200914695-C04. The author H. Carreon wishes to thank CONACYT (Mexico) for the financial support during the sabbatical in CENIM-CSIC.

\section{REFERENCES}

[1] T. Jinno, V.M. Goldberg, D. Davy, S. Stevenson, J.Biomed. Mater. Res A 42:1, (1998) 20.

[2] A. Wennerberg , T. Albrektsson, B. Andersson, Int J Oral Maxillofac Implants 11 (1996) 38.

[3] C. Aparicio, FJ Gil, U. Thams, F. Muñoz, A. Padrós, J.A. Planell. Key Eng Mater 254-256 (2004) 737.

[4] I. Altenberger, B. Scholtes, U. Martin, H. Oettel, Mater Sci Eng A 264:1 (1999) 58. 
[5] J.P. Ferrer, T. Cock, C. Capdevila, F.G. Caballero, C. Garcia, Acta Mater. 55 (2007) 2075.

[6] C. Capdevila C, M.K. Miller, K.F. Russell, J Mat Sci. 43:11 (2008) 3889.

[7] E. López, E. Reyes, A. Martínez-de la Cruz, A. García , M. Morin. J. Alloys Compd, 509:26 (2011) 7297.

[8] E. López , M. Morin, E. Reyes, U. Ortiz , H. Guajardo, J. Yerena J. Alloys Compd, 467:1-2, ( 2009),572.

[9] H. Carreon, P.B. Nagy , M.P. Blodgett, Res. Nondestr. Eval. 14 (2002) 59.

[10] M. Multigner, E. Frutos, J. L. González-Carrasco, J.A. Jiménez, P. Marín, J. Ibáñez. Mater. Sci. Eng. C 29 (2009) 1357.

[11] E. Frutos, M. Multigner, J.L. González-Carrasco, Acta Mater, 58 (2010) 4191.

[12] M. Multigner, S. Ferreira, E. Frutos, M. Jaafar, J. Ibáñez, P. Marín, T. PérezPrado, G. González-Doncel, A. Asenjo, J.L. González-Carrasco. Surf. Coat. Technol. 205 (2010) 1830.

[13] F.G. Caballero, A. García-Junceda, C. Capdevila, C. García de Andrés, Scr. Mater. $52(2005) 501$.

[14] S.Carabajar, J.Merlin, V.Massardier,S. Chabanet, Mater. Sci. Eng. A 281 (2000) 132.

[15] F.G. Caballero, C. Capdevila, L. F. Alvarez, C. García de Andrés, Scr. Mater. 50 (2004) 1061.

[16] J. Hu, P.B. Nagy, Appl. Phys. Lett. 73 (1998) 467.

[17] H. Carreon , NDT \& E Int. 39 (2006) 433.

[18] K. Maslov , V.K. Kinra, Mat. Eval. 59 (2001) 1081.

[19] E. Juzeliūnas , J.P. Wikswo, J. Solid State Electrochem. 10 (2006) 700.

[20] H. Carreon , Wear 265 (2008) 255. 
[21] H. Carreon , J. Alloys Compd, 427:1-2 (2007) 183.

[22] Y.Tavrin, J.Hinken, J. Hallmeyer, Rev. Nondestr Eval.20 (2001) 1710.

[23] G.E. Dieter. Mechanical Metallurgy, third ed., McGraw-Hill Book Company, New York, (1989) 319.

[24] E.O. Hall, Proc. R. Soc. B 64 (1951) 747.

[25] N.J. Petch, J. Iron Steel Mater. 3 (1953) 25.

[26] S.J. Lee, Y.M. Park, Y.K. Lee, Mater. Sci. Eng. A 515 (2009) 32.

[27] M. Sarasola and S. Talacchia, Rev. Metal. 35 (2001) 124. 


\section{Figure Captions}

Figure 1 Cross section SEM images of Alumina blasted 316LVM stainless steel samples a) before and b) after annealing at $700^{\circ} \mathrm{C}$ for $1 \mathrm{~h}$.

Figure 2 Cross section SEM images of Zirconia blasted 316LVM stainless steel samples a) before and b) after annealing at $700^{\circ} \mathrm{C}$ for $1 \mathrm{~h}$.

Figure 3 Microhardness measurements of a) Alumina and b) Zirconia blasted 316LVM stainless steel samples before annealing at $700^{\circ} \mathrm{C}$.

Figure 4 Microhardness values of a) Alumina and b) Zirconia blasted 316LVM stainless steel samples before and after annealing at $700^{\circ} \mathrm{C}$ for several times.

Figure 5 Relative TEP measurements of unblasted and blasted 316LVM stainless steel samples by contacting means.

Figure 6 Magnetic signature of unblasted and blasted 316LVM stainless steel samples by non contacting means. 
a) Un-treated

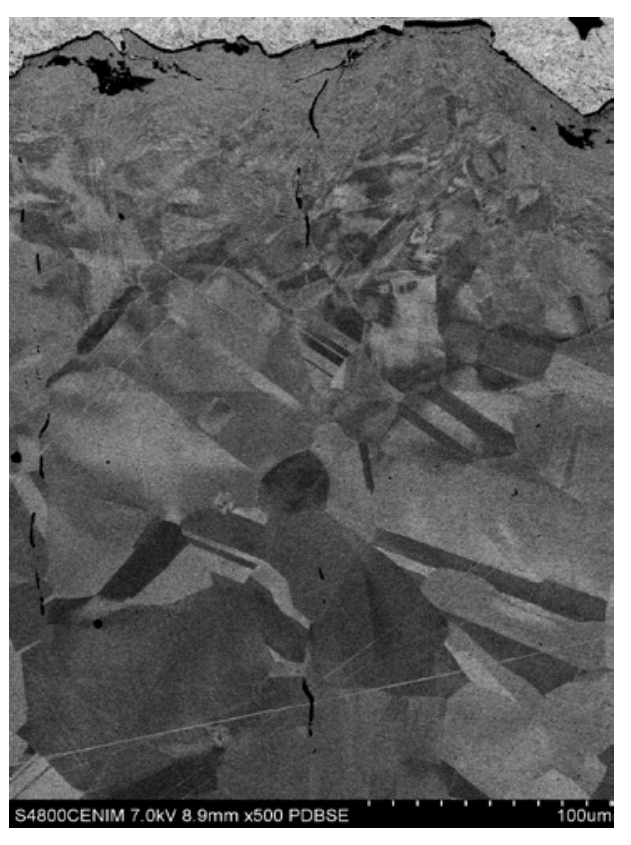

b) $700^{\circ} \mathrm{C}, 1 \mathrm{hr}$

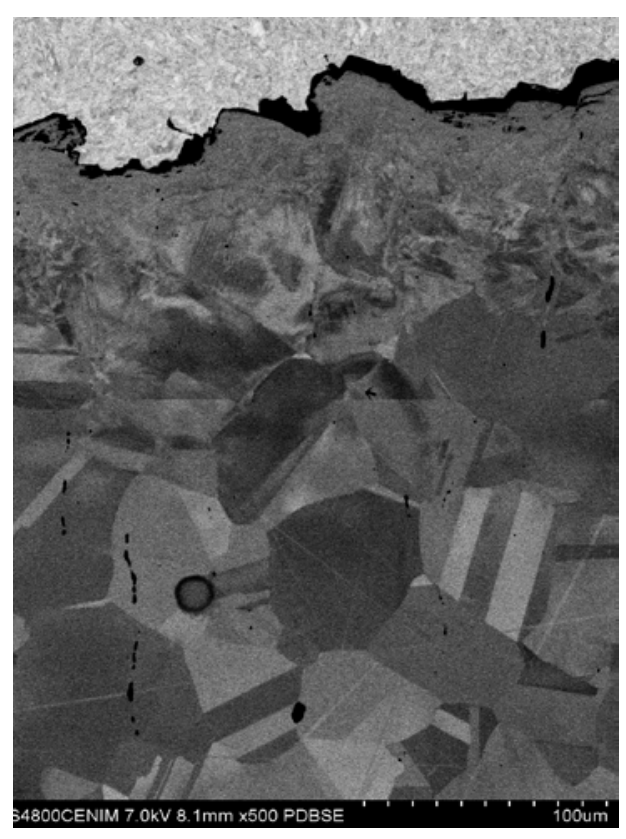

Figure 1.- Cross section SEM images of Alumina blasted 316LVM stainless steel samples a) before and b) after annealing at $700^{\circ} \mathrm{C}$ for $1 \mathrm{~h}$. 
a) Un-treated

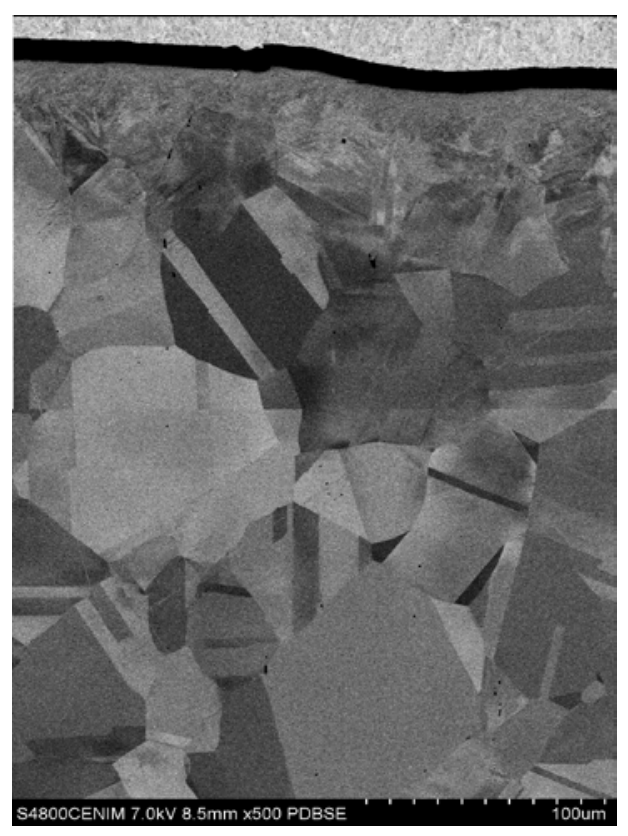

b) $700^{\circ} \mathrm{C}, 1 \mathrm{hr}$

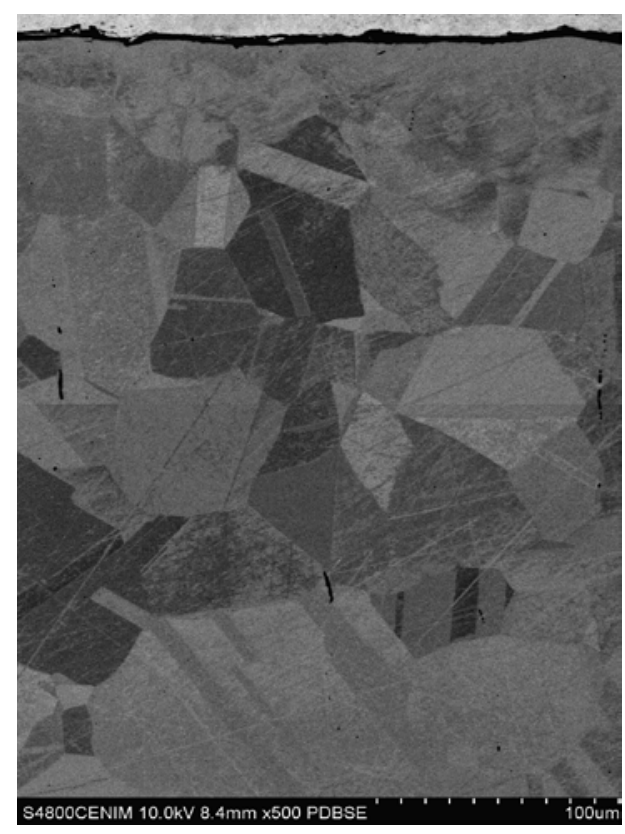

Figure 2.- Cross section SEM images of Zirconia blasted 316LVM stainless steel samples a) before and b) after annealing at $700^{\circ} \mathrm{C}$ for $1 \mathrm{~h}$. 


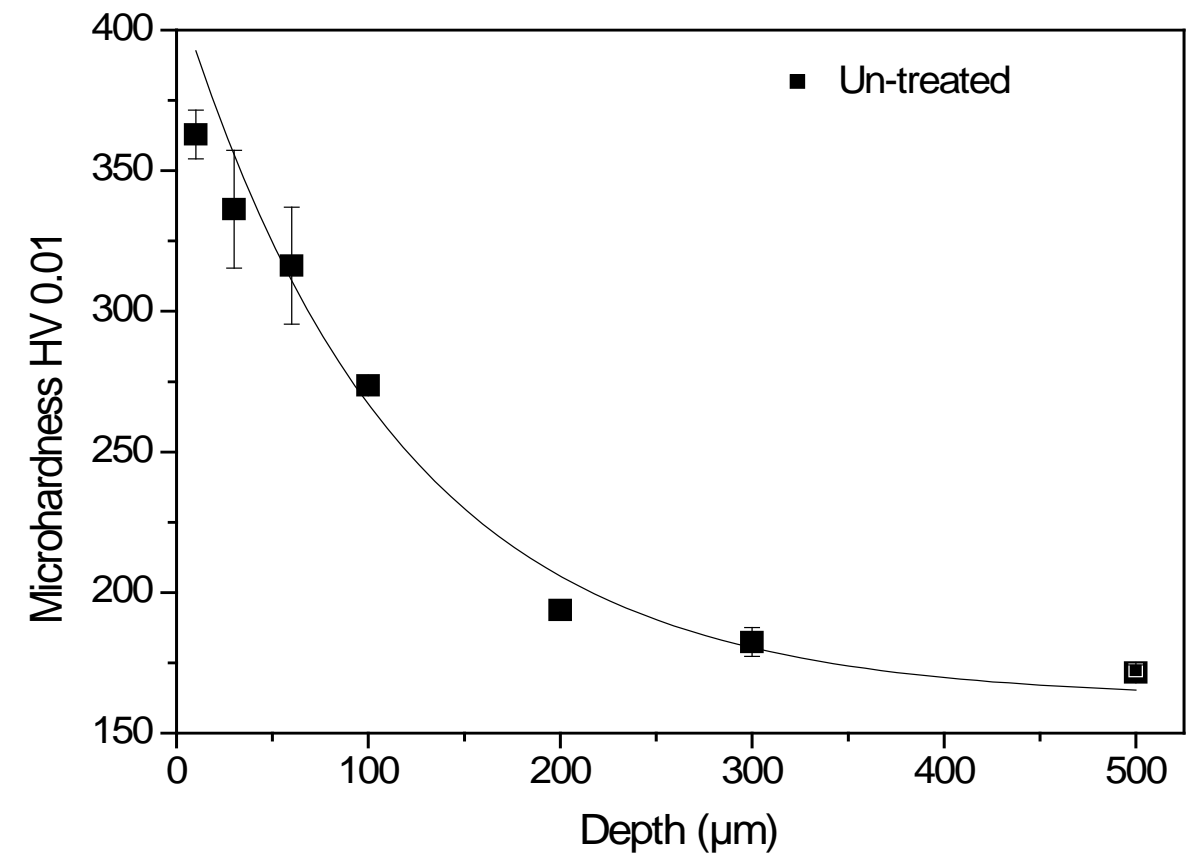

(a)

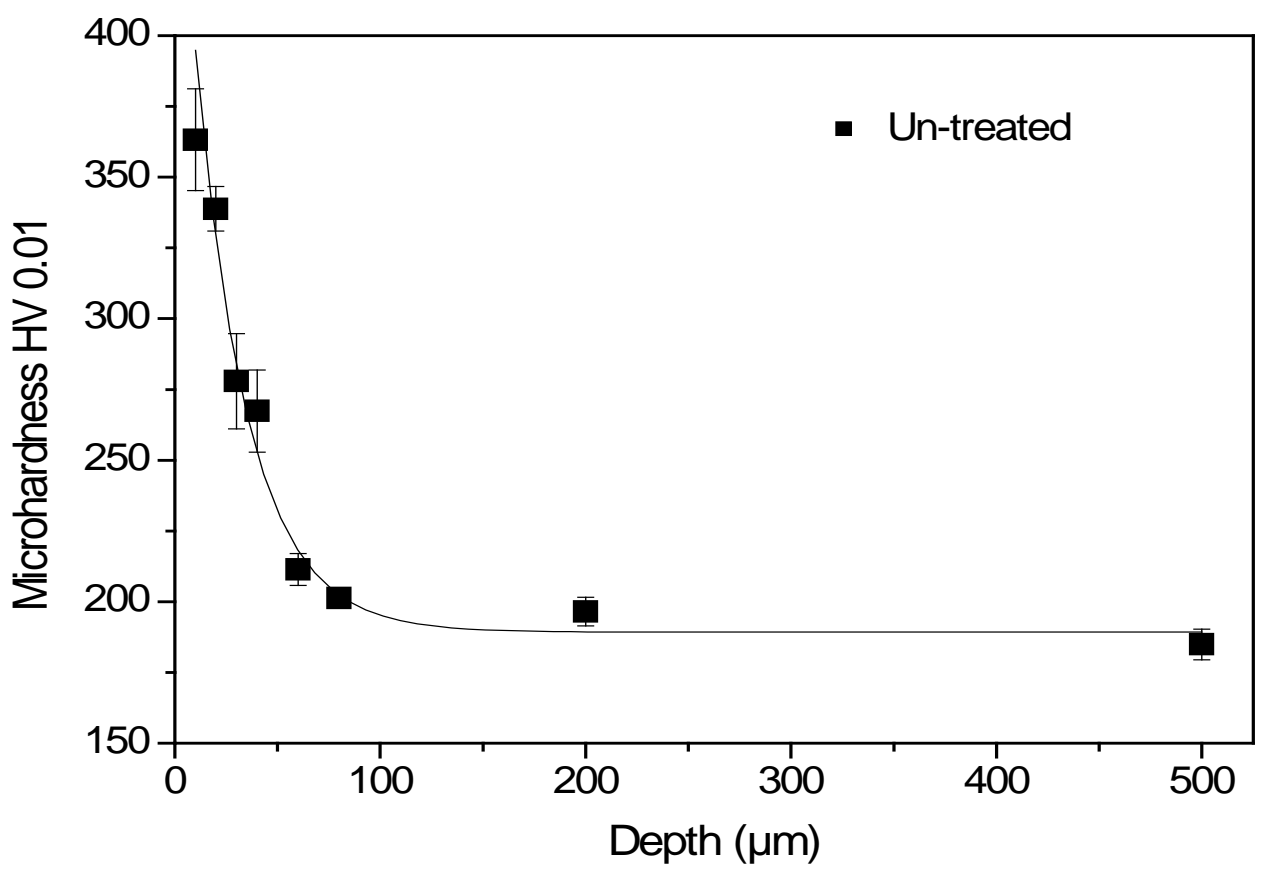

(b)

Figure 3.- Microhardness measurements of a) Alumina and b) Zirconia blasted 316LVM stainless steel samples before annealing at $700^{\circ} \mathrm{C}$. 


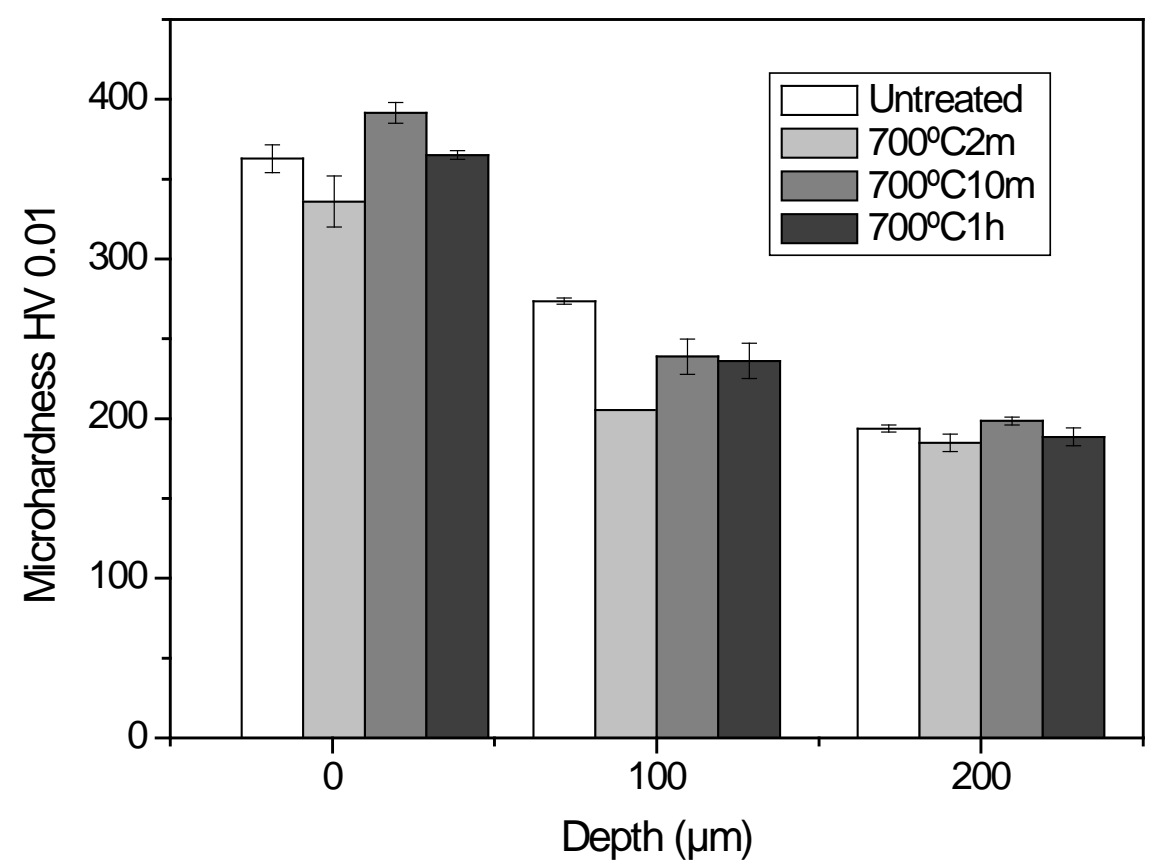

(a)

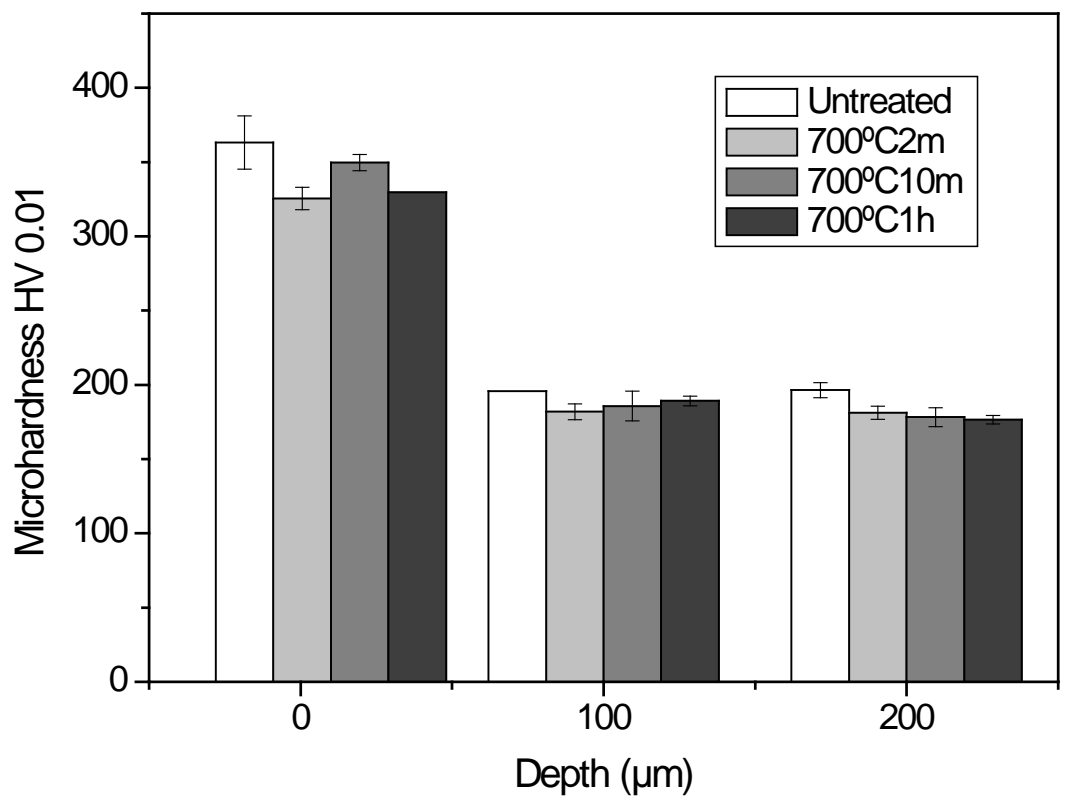

(b)

Figure 4.- Microhardness values of a) Alumina and b) Zirconia blasted 316LVM stainless steel samples before and after annealing at $700^{\circ} \mathrm{C}$ for several times 


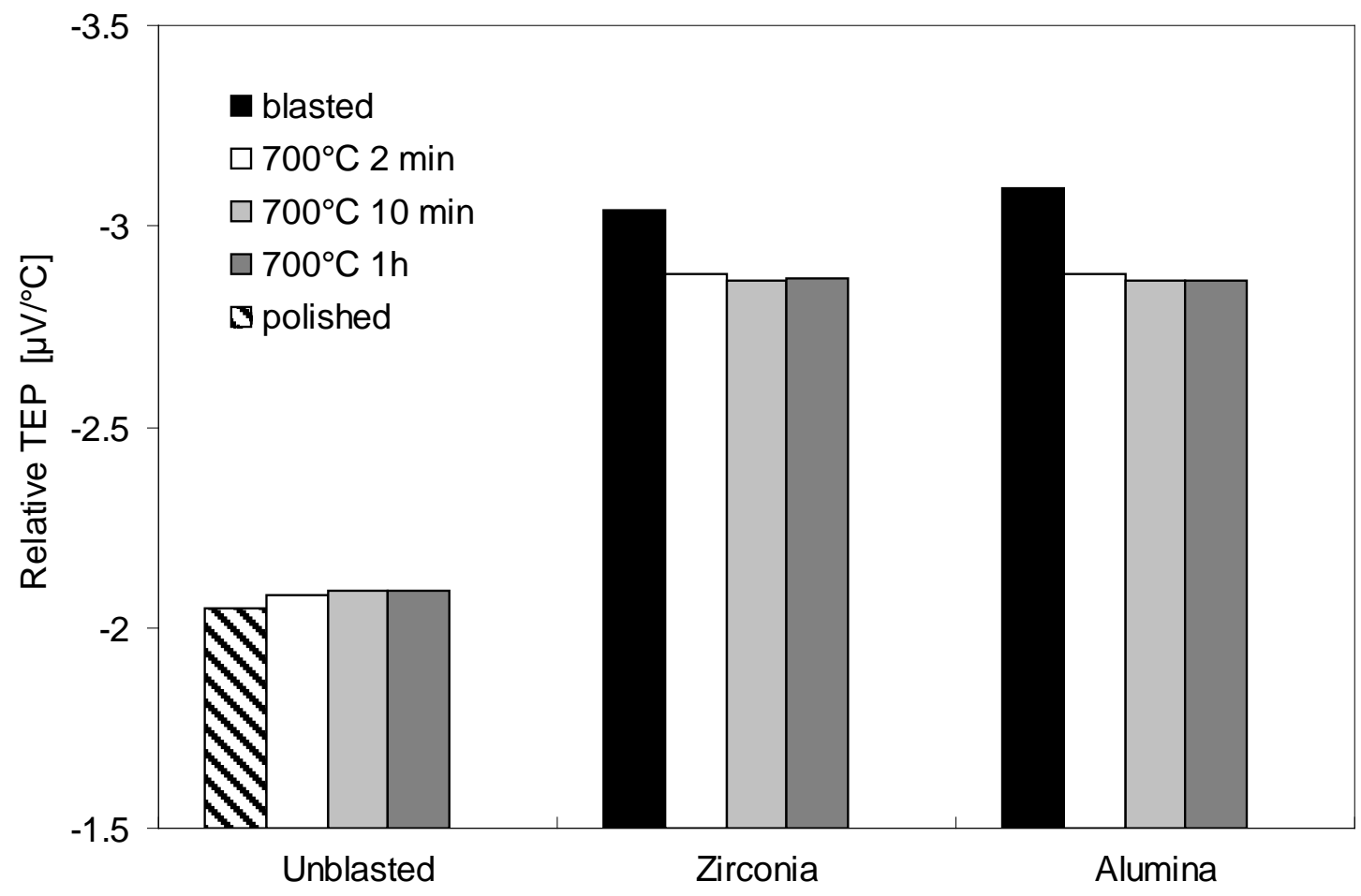

Figure 5.- Relative TEP measurements of unblasted and blasted 316LVM stainless steel samples by contacting means. 


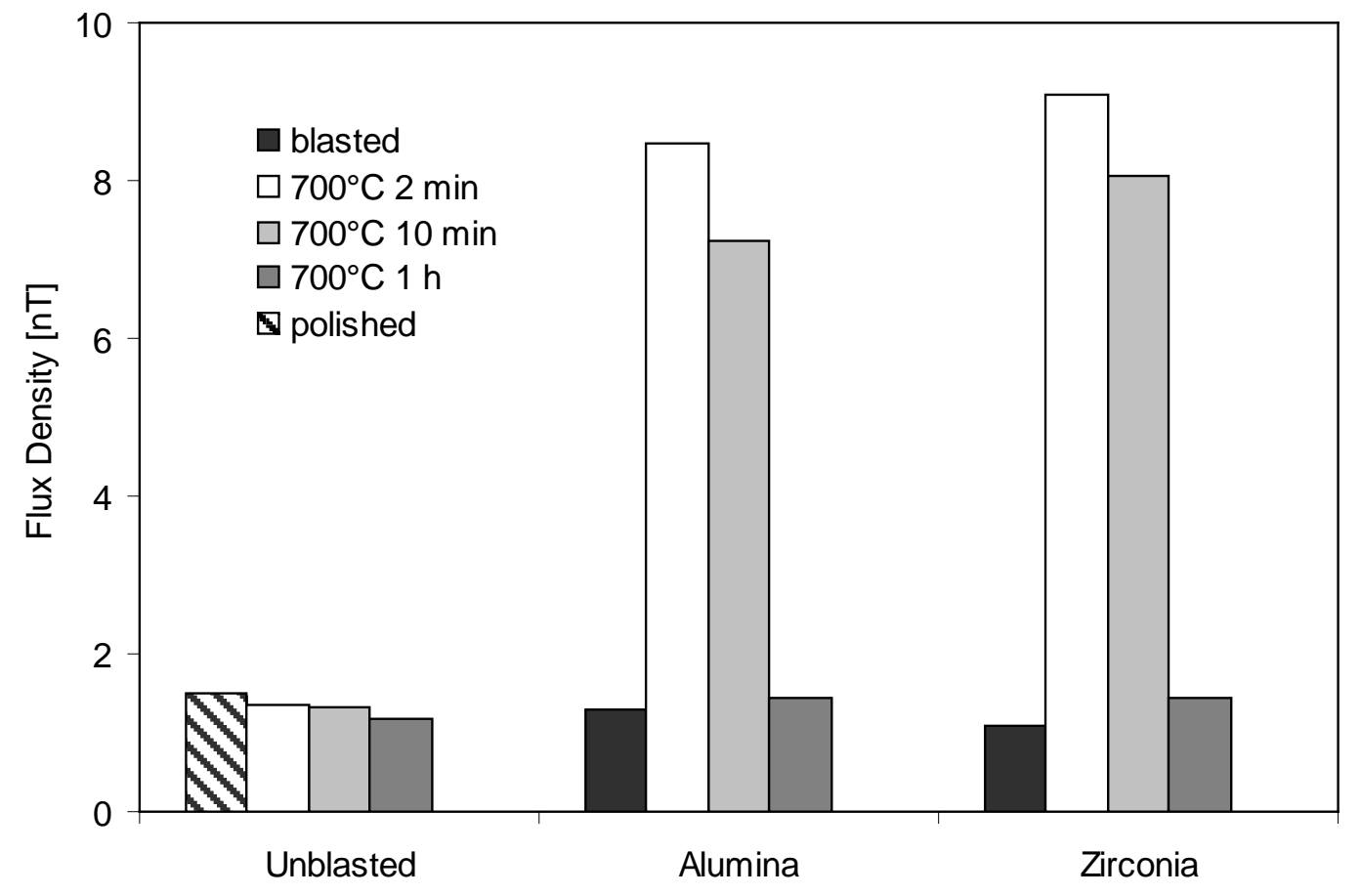

Figure 6.- Magnetic signature of unblasted and blasted 316LVM stainless steel samples by non contacting means. 